This is the final peer-reviewed accepted manuscript of:
Federica Zanetti*, Walter Zegada-Lizarazu, Carla Lambertini, Andrea Monti "Salinity
effects on germination, seedlings and full-grown plants of upland and lowland
switchgrass cultivars"
which has been published in final form in Biomass and Bioenergy 2019, vol. 120, pp.
273-280
The final published version is available online at:
https://doi.org/10.1016/j.biombioe.2018.11.031

(C) 2018 Elsevier. This manuscript version is made available under the Creative Commons Attribution-NonCommercial-NoDerivs (CC BY-NC-ND) 4.0 International License (http://creativecommons.org/licenses/by-nc-nd/4.0/) 


\title{
Salinity effects on germination, seedlings and full-grown plants of upland and lowland switchgrass cultivars
}

\author{
Federica Zanetti*, Walter Zegada-Lizarazu, Carla Lambertini, Andrea Monti \\ DISTAL-Department of Agricultural and Food Sciences, Alma Mater Studiorum, University of Bologna, Viale Giuseppe Fanin 44, 40127, Bologna, Italy
}

\begin{abstract}
A B S T R A C T
Soil salinization is one of the major threats affecting crop production, in particular in the Mediterranean basin where over 1 Mha are salt-affected. Growing lignocellulosic crops, such as switchgrass (Panicum virgatum L.), in marginal saline soils could represent a valuable opportunity to mitigate land abandonment while producing feedstock for biofuels. However, little is still known about salt tolerance of upland and lowland switchgrass cultivars. This study addressed the morphological and physiological responses of Shawnee (upland) and Alamo (lowland) to a range of salinity levels from 0 to $14 \mathrm{dS} \mathrm{m}^{-1}$. Two consecutive experiments were carried out: one in petri dish to test the response to salinity at germination and early growth stages, the other in pot to evaluate the response to salinity until flowering stage (full-grown plants). Both upland and lowland cultivars were able to grow until "critical" salinity levels $\left(14 \mathrm{dS} \mathrm{m}^{-1}\right)$ but their tolerance differed depending on growth stage. Alamo showed a higher tolerance to salinity than Shawnee at very early growth stages (germination/emergence), presenting a germination rate more than double that of Shawnee (60 vs. $19 \%$, main effect cultivar). Nevertheless, Shawnee resulted in a higher tolerance at a full-grown stage likely due to a more efficient salt exclusion capacity, as indicated by the higher residual soil electric conductivity at the end of the experiment detected in Shawnee pots. Final biomass production was anyhow considerably significantly higher in Alamo than Shawnee under any tested salinity level, which demonstrated the improved ability of lowland cultivar to produce biomass compared to Shawnee which otherwise might have invested resources into exclusion mechanisms.
\end{abstract}

Keywords:

Lignocellulose

Perennial grasses

Salt stress

Marginal land

Advanced biofuels

\section{Introduction}

Bioenergy crops might contribute to the rehabilitation of marginal/ abandoned land unsuitable for food crops [1-4]. Saline soils and salineprone soils (agricultural soils irrigated with brackish or saline waters) represent a significant share of European marginal land, as defined by the article 32.3 of European regulation 1305/2013 [5]. Excessive salt levels have been measured in more than 3.8 Mha across Europe [6,7], mostly (about $1 \mathrm{Mha}$ ) located in the Mediterranean basin [8-12]. The main concern is the constant increase in salt content due to human activities such as inappropriate irrigation practices, use of brackish irrigation water, and/or improper drainage systems [13].

Salinity has two main negative impacts on crops growth and productivity: i) reducing plant water uptake capacity due to increased osmotic pressure; ii) accumulating toxic ions (i.e., $\mathrm{Na}^{+}$and $\mathrm{Cl}^{-}$) in plant organs [14]. Plants have evolved mechanisms to adapt to salinity or prevent salinity stress $[14,15]$, such as the control of water flux, accumulation of osmolytes $\left(\mathrm{K}^{+}, \mathrm{Ca}^{2+}, \mathrm{NO}_{3}{ }^{-}\right.$, etc. $)$and maintenance of ion homeostasis (i.e., coupled exchange of $\mathrm{K}^{+} / \mathrm{Na}^{+}$for $\mathrm{H}^{+}$).
Growing perennial lignocellulosic crops for bioenergy and bio-based materials in marginal saline soils might provide economic returns to farmers and several ecosystem services, such as vegetative soil cover, thus mitigating erosion, evaporation, and salinization. It may also be an opportunity to avoid real or perceived competition between energy and food/feed crops. Among other bioenergy crops, switchgrass (Panicum virgatum L.) has been recognized as tolerant to salinity conditions $[13,16]$ due to its ability to promptly adjust its stomatal conductance, osmotic regulation, and to develop salt excretion glands when exposed to salt excess $[17,18]$. This perennial rhizomatous C4 grass, occurring spontaneously from Canada to Mexico, grown in the past as a pasture grass for forage production [19], since ' 80 s it has been identified as a candidate energy crop for USA [20]. In Europe, the research on switchgrass, as a bioenergy crop, is much more recent and dated back to early '90s [21]. The key assets of switchgrass as bioenergy feedstock are: high net energy production, low establishment costs and nutrient requirements, high water-use efficiency, wide geographical adaptation, suitability to marginal soils [22-25]. In its native range in Northern America, switchgrass has evolved two distinct climatic ecotypes: upland

\footnotetext{
* Corresponding author.

E-mail address: federica.zanetti5@unibo.it (F. Zanetti).
} 
and lowland [26]. In general, upland ecotypes are adapted to the dry climate of the high altitude prairies, while lowlands are riparian plants and occur in warmer climates at lower altitudes and latitudes [27-29]. The uplands are generally considered more tolerant to salinity [30] than lowlands; nevertheless, regardless of ecotype, massive variation in salt tolerance was observed among switchgrass cultivars [31]. Different authors $[30,32]$ reported that Alamo (lowland) had a moderate tolerance to salinity, whereas Cave-in-Rock (upland) suffered considerable negative effects on germination rate and speed at only $5 \mathrm{dS} \mathrm{m}^{-1}$ [17]. The extent of salt tolerance and acclimation mechanisms remain however poorly known, especially the effects of salt stress on seedling growth that is the stage at which plants are generally more sensitive to salt stress [18]. Highly productive cultivars (i.e., lowland), poorly tolerant to salinity, might dramatically decrease biomass yield if grown on salt-affected land; thus, for example, a switchgrass upland cultivar, despite its lower potential productivity under Mediterranean climate, might be preferred in such conditions.

In view of a possible spreading of switchgrass cultivation, as a bioenergy crop, into Mediterranean marginal soils, affected by salinity, the main objective of the present study was to evaluate the morphophysiological responses to salinity stress of an upland (Shawnee) and a lowland (Alamo) switchgrass cultivar. The two cultivars were selected basing on long-term trials comparing upland and lowland cultivars under Northern Mediterranean conditions [33].

\section{Materials and methods}

\subsection{Plant material and salinity treatments}

Two consecutive experiments were performed under controlled environments with the aim at comparing salinity tolerance of Shawnee (upland cultivar) and Alamo (lowland cultivar). Certified 3-year-old switchgrass seed of Alamo and Shawnee were supplied by NaturRohstoff-Service (Germany). The germination test supplied with the switchgrass seeds (AOSA standard, $15-30{ }^{\circ} \mathrm{C}, 7-14 \mathrm{~h}$ day/night) revealed germination rates of $55 \%$ (38\% dormant seeds, TZ test) and $72 \%$ (7\% dormant seeds, TZ test) for Shawnee and Alamo, respectively. Once arrived, switchgrass seeds were stored at $15{ }^{\circ} \mathrm{C}$ and $50 \% \mathrm{RH}$ until experiment start, thus authors assumed that seed dormancy was completely broken, as reviewed by Ref. [34]. Four salinity levels were used in both experiments (Table 1).

The effects of salinity stress $\left(0,6,8\right.$ and $14 \mathrm{dS} \mathrm{m}^{-1}$ indicated as S1, S2, S3 and S4, respectively) were determined on young (seedlings) (Exp. 1) and full-grown (flowering stage) plants (Exp. 2). In both experiments, control plants (S1) were watered using tap water (water conductivity always lower than $0.8 \mathrm{dS} \mathrm{m}^{-1}$ ). Saline solutions were obtained adding $\mathrm{NaCl}$ to tap water in order to obtain the desired salinity levels (Table 1). Imposed salinity stress levels were chosen to be comparable with data available in the literature for similar species [32]. The electrical conductivity of tap water and salinity solutions were measured by a pH/EC portable conductivity meter (HI 98130, Hanna Instruments, Italy).

Table 1

Salinity levels $(\mathrm{NaCl}+$ tap water) used in Exp. 1 and 2 .

\begin{tabular}{lllll}
\hline Treatment & Salinity $\left(\mathrm{dS} \mathrm{m}^{-1}\right)$ & $\mathrm{NaCl}\left(\mathrm{g} \mathrm{l}^{-1}\right)$ & \multicolumn{2}{l}{ Soil EC $\left.(\mathrm{dS} \mathrm{m})^{-1}\right)^{\mathrm{a}}$} \\
\cline { 4 - 5 } & & & Alamo & Shawnee \\
\hline S1 & $<0.8$ (control) & 0 & 0.24 & 0.34 \\
S2 & 6 & 2.92 & 1.03 & 1.48 \\
S3 & 8 & 4.19 & 1.79 & 1.90 \\
S4 & 14 & 8.01 & 2.75 & 4.29 \\
\hline
\end{tabular}

${ }^{a}$ Soil electrical conductivity (EC) measured at the end of the Exp. 2.

\subsection{Exp. 1: salt tolerance during germination and early seedling growth}

Alamo and Shawnee were sown on a blue blotter paper (Anchor, St. Paul, USA) in transparent boxes (dimensions $120 \times 180 \times 70 \mathrm{H} \mathrm{mm}$, Loire Plastic Industrie, France). The blue color facilitated the identification of roots and shoots during measurements (length) due to contrasting background. Thirty seeds were equidistantly arranged in two rows (15 seeds per row), $100 \mathrm{~mm}$ apart, in each box.

Three consecutive trials were set in a germination chamber (ALS Angelantoni Life Science, Italy) with temperatures of $20^{\circ} \mathrm{C}, 25^{\circ} \mathrm{C}$ and $30^{\circ} \mathrm{C}(8 / 16 \mathrm{~h}$ day/night), respectively, adopted as typical mean daily temperatures during the ideal sowing period (April to May) for switchgrass under north Mediterranean climate. In all trials, a set of 40 plexiglass boxes ( 2 cultivars $\mathrm{x} 4$ salinity levels $\mathrm{x} 5$ replications) was used. Seeds were watered, using the aforementioned solutions (S1-4, Table 1), every other day by a syringe being careful not to directly wet the seeds. Five days after the beginning of the experiment the germination boxes were $45^{\circ}$ tilted in order to facilitate plumular and radicular length measurements at the end of the experiment. Germination rate was determined weekly starting from seven days after sowing (DAS). Germination rate of control plants was similar to that referred on the germination tests provided by the seed supplier. Germination was considered concluded when the number of germinated seeds in two consecutive measurements remained the same. At the end of each trial, the germination paper was removed from the plexiglass boxes with all grown seedlings stuck on it and turned upside down on a transparent film, and placed into a scanner (CanonScan $3000 \times$, Canon, Japan) to capture digital images (300 DPI) of plumule and radicle of switchgrass seedlings (Fig. 1). Images were manually drawn (Fig. 1) by an interactive pen display (Wacom Co. Ltd., Japan) and then processed by ImageJ software (National Health Institute, Bethesda, USA) to determine their lengths.

\subsection{Exp. 2. salt tolerance during shoot elongation until reproductive-floral development}

Fifty seeds of Alamo and Shawnee cultivars were sown $(5 \mathrm{~mm}$ depth) in truncated square pyramid pots $(140 \times 140 \times 160 \mathrm{~mm})$ filled with $2500 \mathrm{~g}$ of sandy soil characterized by: $\mathrm{pH} 8.25$, OM $0.92 \%$, total $\mathrm{N}$ $0.47 \mathrm{~g} \mathrm{~kg}^{-1}$. After emergence, the plants were thinned out to a density of ten plantlets per pot. Thereafter, forty pots (4 salinity levels $\mathrm{x} 2$ cultivars $\mathrm{x} 5$ replications) were placed into a growth chamber with controlled environment $\left(28 / 22^{\circ} \mathrm{C}\right.$ day/night temperature, $12 \mathrm{~h}$ day/ night photoperiod, $60 \% \mathrm{RH}$, and $300 \mu \mathrm{mol} \mathrm{m}^{-2} \mathrm{~s}^{-1}$ of PAR). Temperature settings were chosen as those minimizing salinity effects on switchgrass germination, derived from resulted obtained in Exp. 1 results. Salt treatments started at the $3^{\text {rd }}$ leaf stage (V3 phenological growth stage as given by Moore et al. [35]), corresponding to 50 DAS and 441 GDD (Growing Degree Days). GDD were calculated as the sum of temperature differences between the mean daily temperature and the base temperature (i.e., for switchgrass $10^{\circ} \mathrm{C}$ [36]). GDD were adopted to more easily compare the obtained results to the developmental stage of the crop under field conditions. Pots were irrigated to maintain field capacity $(23 \% \mathrm{v} / \mathrm{v})$ when soil water content went below $20 \%$ in half of the pots. The precise amount of water applied to each individual pot was gravimetrically determined, avoiding any leaching. Hydro-soluble fertilizer (20-20-20, NPK) was monthly applied to keep the plants under not limiting conditions.

During switchgrass growth, photosynthesis (Amax) and maximum quantum yield of photosystem II (Fv/Fm) were determined every $\sim 15 \mathrm{~d}(\sim 230 \mathrm{GDD})$ after the beginning of salt treatment. The Fv/Fm was determined through chlorophyll a fluorescence ( $\mathrm{Chl} a$ ) emission measurements. Fluorescence emissions were produced by a continuous excitation chlorophyll fluorimeter (Handy PEA, Hansatech Instruments, UK) providing the high time resolution essential in performing measurements of fast fluorescence induction kinetics. Measurements were 

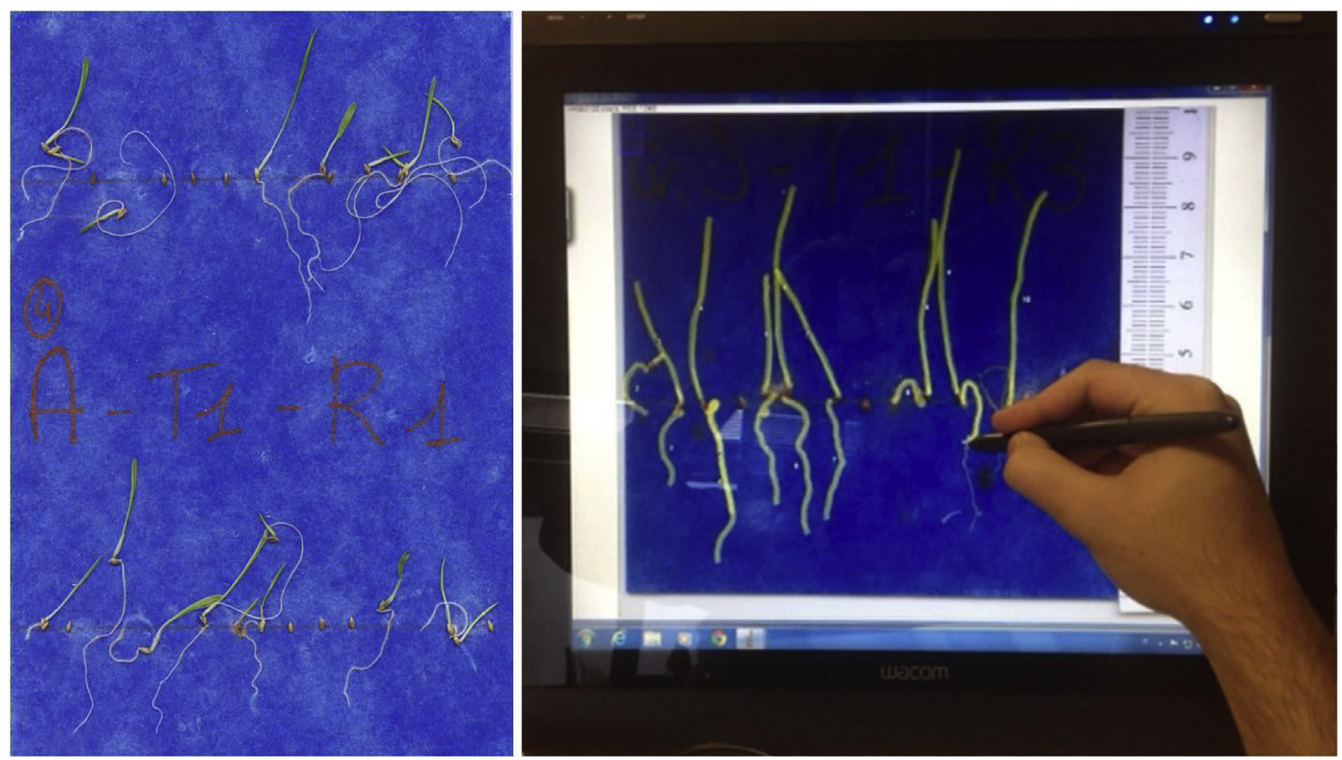

Fig. 1. (Left) Digital images of plumule and radicle of switchgrass seedlings in Exp. 1. (Right) Manually drawn switchgrass seedling images before software processing.

carried out on two top fully expanded leaves per plant, which later on were averaged. Before measurements, leaves were dark acclimated for $30 \mathrm{~min}$ into leaf-clips in order to allow the complete oxidation of quinone pool in the electron transport system. The Amax was determined by a portable infrared gas analyzer (CIRAS-2, PPSystems, UK) in top fully expanded leaves adjacent to the ones used for fluorescence determinations. During measurements, the environmental conditions inside the cuvette were set at $1500 \mu \mathrm{mol} \mathrm{m}^{-2} \mathrm{~s}^{-1}$ photosynthetic photons flux density (PPFD), and $380 \mu \mathrm{mol} \mathrm{mol}^{-1}$ of $\mathrm{CO}_{2}$. The response of some photosynthetic gas exchange parameters (photosynthetic rate, stomata conductance, leaf internal $\mathrm{CO}_{2}$ concentration, and transpiration) were recorded after steady state was reached ( $\mathrm{CV}<1.0 \%$ ). The experiment was considered concluded when the plants under the highest salinity level (S4, Table 1) showed photosynthetic rates below $2 \mu \mathrm{mol} \mathrm{CO} \mathrm{CO}^{-2}$ $\mathrm{s}^{-1}$ in two consecutive measurements. Exp. 2 lasted in total $2160 \mathrm{GDD}$ ( $\sim 190 \mathrm{~d}$ ) from sowing to the final sampling. After the last irrigation ( $4 \mathrm{~d}$ before the final sampling), soil electrical conductivity was measured on each pot by a conductivity meter (SMEC 300 series, Spectrum Technologies Inc., UK) connected to a data logger (WatchDog micro Station) at field capacity and $26^{\circ} \mathrm{C}$.

The above- and belowground biomass (FW) of single plants were collected, oven dried at $60^{\circ} \mathrm{C}$ until constant weight, then weighted to determine the dry weight (DW). Leaf water content (LWC) was evaluated from total aboveground biomass measurement at harvest, and water content was calculated as follows: LWC $\left(\mathrm{g} \mathrm{g}^{-1}\right)=(\mathrm{FW}-\mathrm{DW}) / \mathrm{DW}$, where FW is leaf fresh weight and DW is leaf weight after oven-drying. Sodium content of aboveground biomass was determined as follows: $0.250 \mathrm{~g}$ of biomass was ground and digested using $8 \mathrm{ml}$ of concentrated Suprapur nitric acid (Merck) plus $2 \mathrm{ml}$ of hydrogen peroxide (Carlo Erba for electronic use) in a microwave oven (Start D 1200, Milestone). The mineralization was carried out in PTFE bombs in the microwave oven, and the content of $\mathrm{Na}$ was quantified by inductively coupled plasma spectrometry (ICP-OES, SPECTRO Arcos, Ametek, Kleve, Germany). The accuracy of the instrumental method and analytical procedures was checked by triplication of the samples, as well as by using reference material, which was run after every 10 samples to check for drift in the sensitivity. The analytical quality of the results was checked against CRM 062 (Olive leaves) the following reference material (provided by the European Commission Institute for Reference Materials and Measurements), which certifies values of the studied elements close to the measured ones.

\subsection{Statistical analysis}

Prior to analysis of variance (ANOVA), Bartlett's test was used to verify homoscedasticity of data variance, and percentage data (germination rate in the Exp. 1) were transformed into square root. In the Exp. 1 , the three-way ANOVA was used to test the interactions between salinity and cultivar, and salinity and temperature. In the Exp. 2, the repeated measure multifactor ANOVA was used to test the effects of salinity over time on non-destructive parameters (Amax, Fv/Fm). For the parameters measured at the final sampling, a two-way ANOVA was used to test the effect of cultivar and salinity and their interaction. When ANOVA revealed statistically different means, the Bonferroni's test was used to separate means in different groups $(P \leq 0.05)$. The SYSTAT ver. 13.2 (Systat Software Inc., USA) statistical software was used to carry out the data analysis.

\section{Results}

\subsection{Exp. 1: salt tolerance during seed germination and early seedling} development

The ANOVA results for Exp. 1 are reported on Table 2. With the aim of specifically studying only the effect of salinity stress on switchgrass, authors considered the evaluation the main effect of temperature and the interaction "cultivar $x$ temperature" out of the scope of the present study, while the interactions "salinity x cultivar" and "salinity $\mathrm{x}$ temperature" are presented and discussed. Germination rate was affected $(P \leq 0.05)$ by cultivar, temperature and salinity (Fig. 2a), and the interaction between salinity and temperature (Fig. 2b). Germination rates, weighted on control plants, revealed that salinity decreased germination by $41 \%$ and $22 \%$ in Shawnee and Alamo, respectively. At $25{ }^{\circ} \mathrm{C}$, salinity effect on switchgrass germination was more restrained and differences among treatments were not significant (Fig. 2b), while at $20^{\circ} \mathrm{C}$, and to a lower extent at $30^{\circ} \mathrm{C}$, germination rate dramatically decreased in $\mathrm{S} 4\left(-64 \%\right.$ at $20^{\circ} \mathrm{C}$ compared to the germination rate occurred at $25^{\circ} \mathrm{C}$ in $\mathrm{S} 4$ ).

Similar to the germination rate, also plumular and radicular lengths were influenced by salinity with the significant lowest values associated to S4 treatment. The salinity effects on radicular and plumular development differed between upland and lowland ecotypes. Alamo progressively decreased both radicular and plumular length with 
Table 2

ANOVA results. Factors: $\mathrm{C}=$ cultivar (Shawnee and Alamo), $\mathrm{S}=$ salinity $(0,6$, 8 and $\left.14 \mathrm{dS} \mathrm{m}^{-1}\right), \mathrm{T}=$ temperature $\left(20,25\right.$ and $\left.30^{\circ} \mathrm{C}\right)$. Germ $=$ germination rate; Plumule = plumular length; Radicle $=$ radicular length; Amax $=$ photosynthetic assimilation rate; $\mathrm{Fv} \backslash \mathrm{Fm}=$ maximum quantum yield, LWC = leaf water content; Shoot $=$ individual shoot dry biomass; Root $=$ individual root dry biomass; $\mathrm{Na}=$ sodium concentration in the shoot. * and $* *=$ significance levels for $* P \leq 0.05$ and 0.01 , respectively (n.s. $=$ not significant).

\begin{tabular}{|c|c|c|c|c|c|c|c|c|c|}
\hline \multirow{2}{*}{$\begin{array}{l}\text { Source of } \\
\text { variation }\end{array}$} & \multicolumn{3}{|c|}{ Experiment 1} & \multicolumn{6}{|c|}{ Experiment 2} \\
\hline & Germ & Plumule & Radicle & Amax & $\mathrm{Fv} \backslash \mathrm{Fm}$ & LWC & Shoot & Root & $\mathrm{Na}$ \\
\hline $\mathrm{C}$ & $* *$ & $* *$ & n.s. & $* *$ & $* *$ & * & $* *$ & n.s. & $* *$ \\
\hline S & $* *$ & $* *$ & $* *$ & *** & $* * *$ & *** & ** & *** & $* *$ \\
\hline $\mathrm{T}$ & $* *$ & $* *$ & $* *$ & - & - & - & - & - & - \\
\hline $\mathrm{C} \times \mathrm{S}$ & n.s. & $* *$ & n.s. & $* *$ & * & * & * & n.s. & $* *$ \\
\hline $\mathrm{C} \times \mathrm{T}$ & n.s. & $* *$ & $* *$ & - & - & - & - & - & - \\
\hline $\mathrm{T} \times \mathrm{S}$ & $* *$ & n.s. & n.s. & - & - & - & - & - & - \\
\hline $\mathrm{C} \times \mathrm{S} \times \mathrm{T}$ & n.s. & n.s. & n.s. & - & - & - & - & - & - \\
\hline
\end{tabular}

increasing salinity from S1 to S4 (Fig. 3), but the reduction was much higher for shoots $(-62 \%)$ than for roots $(-34 \%)$ compared to untreated plants (S1). Shawnee presented significant longer plumules than Alamo under any salinity treatment, while radicular length was similar between the two cultivars. Also in Shawnee the reduction in response to salinity was higher for shoots $(-65 \%)$ than for roots $(-29 \%)$. The interaction salinity $\mathrm{x}$ cultivar (Table 2 \& Fig. 3) was significant for plumular length with Alamo reducing its growth proportionally to salinity increase, while Shawnee showed similar values in S1 and S2, while an evident reduction appeared at salinity above $8 \mathrm{dS} \mathrm{m}^{-1}$.

\subsection{Exp. 2. salt tolerance during shoot elongation until reproductive-floral} development

The ANOVA results for Exp. 2 are reported on Table 2. Since all the gas exchange parameters evaluated in Exp. 2 (photosynthetic rate, stomata conductance, leaf internal $\mathrm{CO}_{2}$ concentration, and transpiration) followed a similar trend, only the changes of the photosynthetic rates of both cultivars in response to salinity level and time are presented later on. Salinity negatively affected Amax to a different extent depending on cultivar and growth stage (Table 2 and Fig. 4). In Alamo, Amax decreased from S1 to S4 throughout the studied growth period, whereas Shawnee maintained a similar Amax in all salinity treatments until GDD 1773, thereafter it sharply decreased in S4. Consistently with Amax, Fv/Fm in both cultivars and all salinity levels slightly decreased with time until GDD 1773, thereafter dramatically dropped only in S4 (data not shown).

As expected, LWC generally decreased with salinity; however, it differently changed in Alamo and Shawnee (Table 2): higher values surveyed in Alamo than in Shawnee. The interaction salinity x cultivar was also significant (Table 2), in particular Alamo decreased LWC linearly with salinity increase, while the plants of Shawnee reported a significant decrease only under the highest stress (S4), with halved LWC value compared to Alamo in the same conditions ( 0.81 vs. $1.56 \mathrm{~g} \mathrm{~g}^{-1}$ in Shawnee and Alamo, respectively).

In general, Alamo produced more than triple shoot biomass than Shawnee in S1, S2 and S3 and more than double shoot biomass in S4 (Figs. 5 and 6). In contrast, root dry weight of the two cultivars was very similar in all salinity treatments, except for S3 in which Alamo showed a higher root biomass than Shawnee (Fig. 6). Moderate (S3) and high (S4) salt stresses caused significant reductions of shoot biomass only in Alamo (Fig. 6), while salinity never affected Shawnee shoot biomass. On the other hand, belowground biomass decreased with salinity in both cultivars (Fig. 6): Alamo and Shawnee showed comparable root growth under S1 and S2, with significant decreases becoming evident at salinity above $8 \mathrm{dS} \mathrm{m}^{-1}$.

With regard to $\mathrm{Na}^{+}$accumulation in shoot biomass, a significant effect of "salinity x cultivar" interaction was found (Fig. 7). In general, $\mathrm{Na}^{+}$content was similar in S1 and S2, and it significantly increased in S3 and S4, to a greater extent in Shawnee that had more than double shoot $\mathrm{Na}^{+}$content than Alamo in S4 (Fig. 7). A general negative relationship between biomass production and $\mathrm{Na}^{+}$shoot content was found; in particular, belowground biomass significantly decreased with increased $\mathrm{Na}^{+}$content in both cultivars (Fig. 8), whereas the aboveground biomass decreased only in Alamo. Shoot $\mathrm{Na}^{+}$content resulted also negatively related with measured physiological traits (Amax, Fv $\backslash$ Fm and LWC), but not Fv/Fm in Shawnee (Table 3). Moreover, Alamo showed a faster decline of Amax in response to salinity (Table 3).

\section{Discussion}

The United Nations Environment Program highlighted the extreme relevance of salt-affected agricultural land [37], and in particular in the Mediterranean basin where salinity is constantly increasing [8-12]. Switchgrass is one of the most interesting lignocellulosic crops for its high biomass production thus it could be a good candidate for salt-stress land of the Mediterranean basin; nonetheless, knowledge on salinity effects on switchgrass (including upland and lowland cultivars) appears to remain incomplete. We are aware of a very limited number of studies comparing salt tolerance of lowland and upland switchgrass cultivars $[31,38,39]$. Moreover, in these studies, salinity effects were investigated only in young plants or over short periods [31,40], and
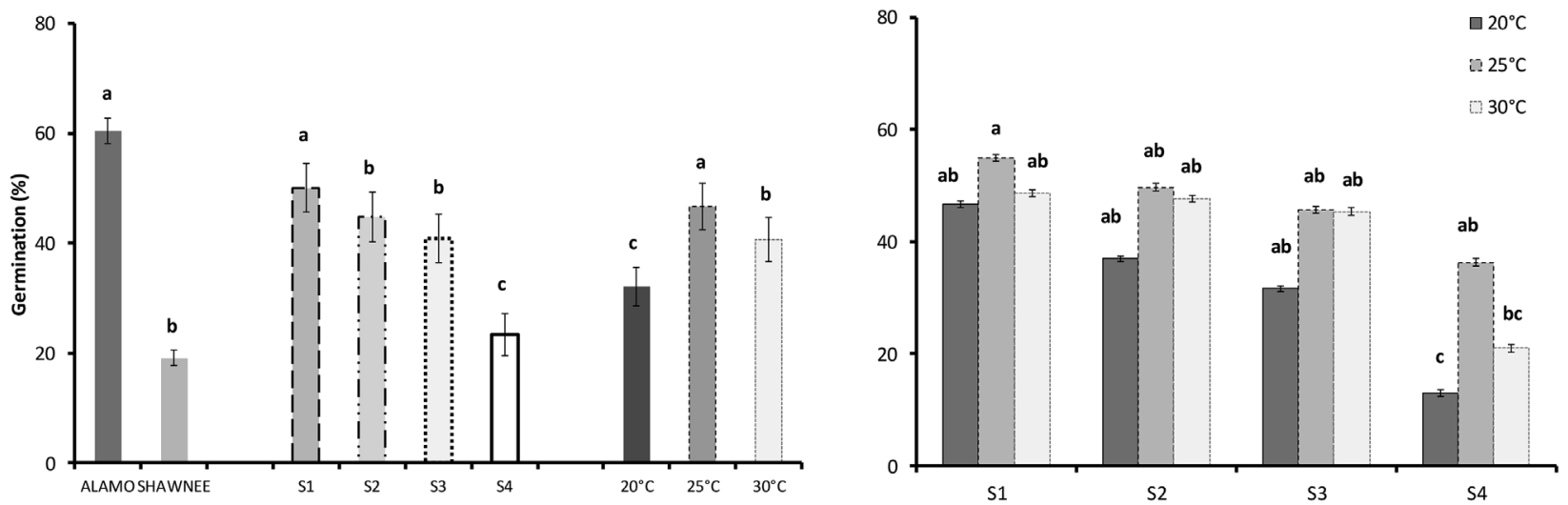

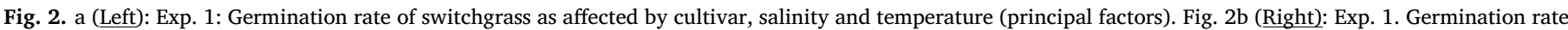

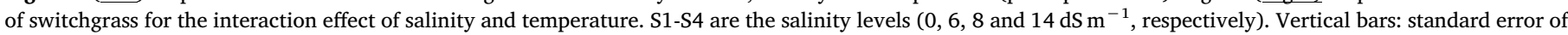

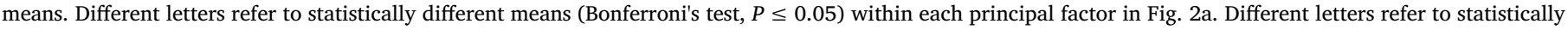
different means (Bonferroni's test, $P \leq 0.05$ ) for the interaction "salinity x temperature" in Fig. 2 b. 


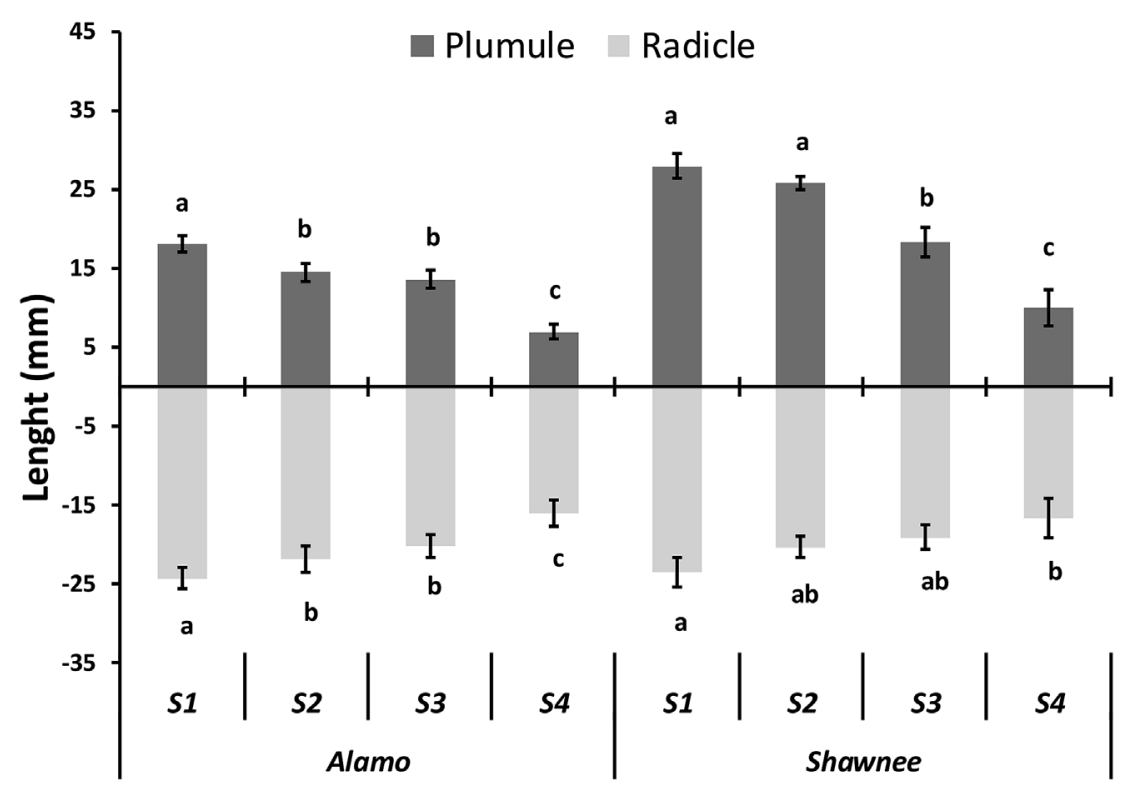

Fig. 3. Exp. 1: radicular and plumular lengths of Alamo and Shawnee in response to salinity. S1-S4, salinity levels: 0, 6, 8 and 14 dS $\mathrm{m}^{-1}$, respectively. Vertical bars: standard error of means. Different letters refer to statistically different means (Bonferroni's test, $P \leq 0.05$ ) within each plant part and cultivar.
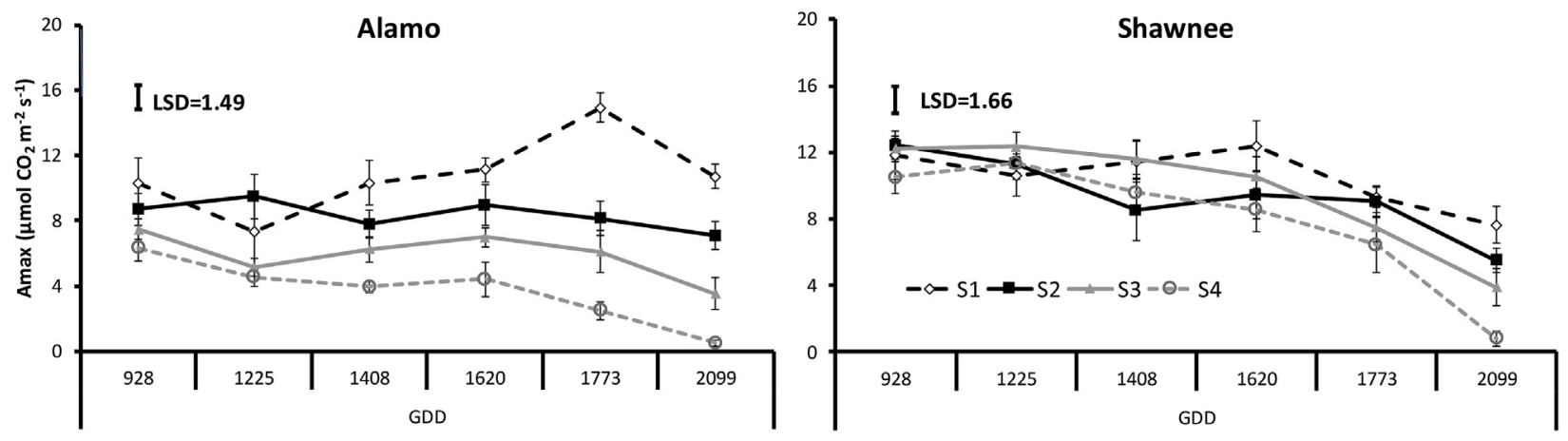

Fig. 4. Exp. 2: time course (GDD, growing degree days) of light saturated rate of photosynthesis (Amax) of Alamo (left figure) and Shawnee (right figure). S1-S4 are the salinity levels $\left(0,6,8\right.$ and $14 \mathrm{dS} \mathrm{m}^{-1}$, respectively). Vertical bars: standard error of means. LSD: least significant difference among photosynthetic rates within the same cultivar $(P \leq 0.05$, Bonferroni's test).
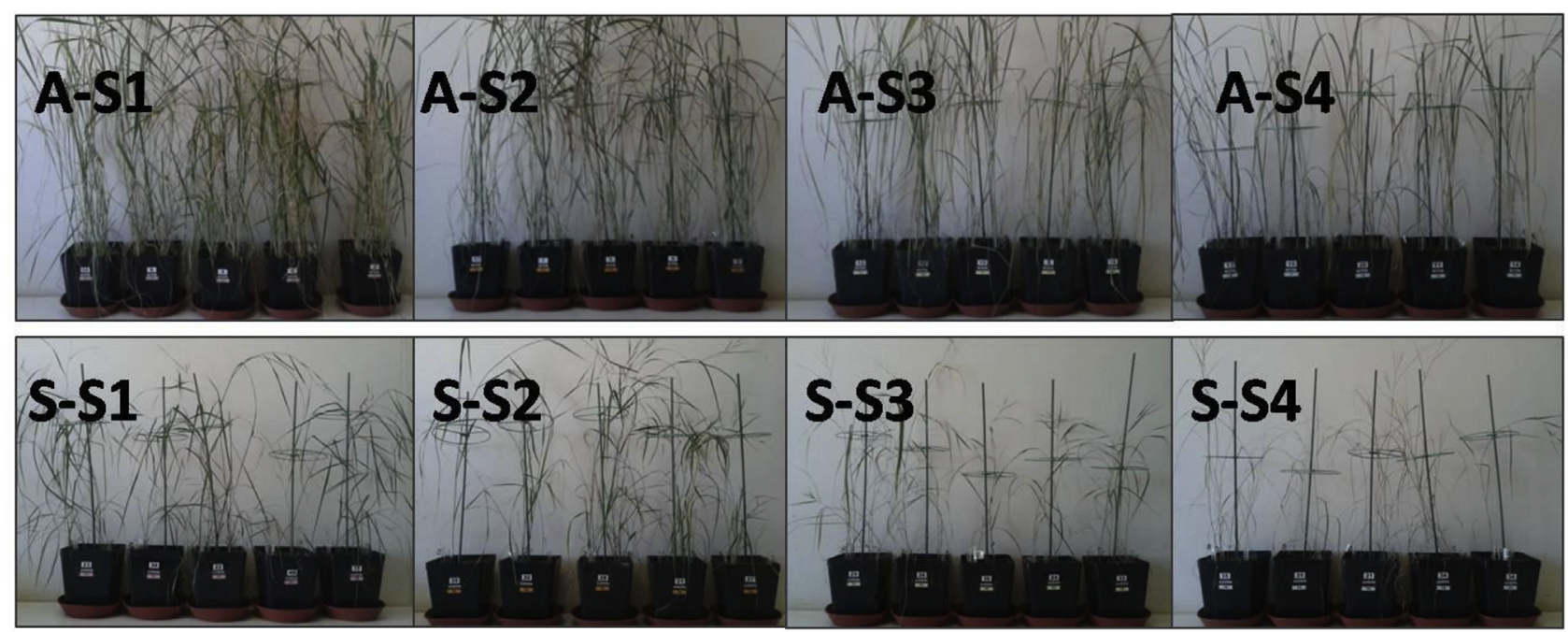

Fig. 5. Exp. 2. Alamo (above pictures) and Shawnee (below pictures) immediately before final biomass harvest (GDD $=2099)$. The first letter on each picture indicate Alamo (A) or Shawnee (S). S1-S4 are the salinity levels $\left(0,6,8\right.$ and $14 \mathrm{dS} \mathrm{m}^{-1}$, respectively). 


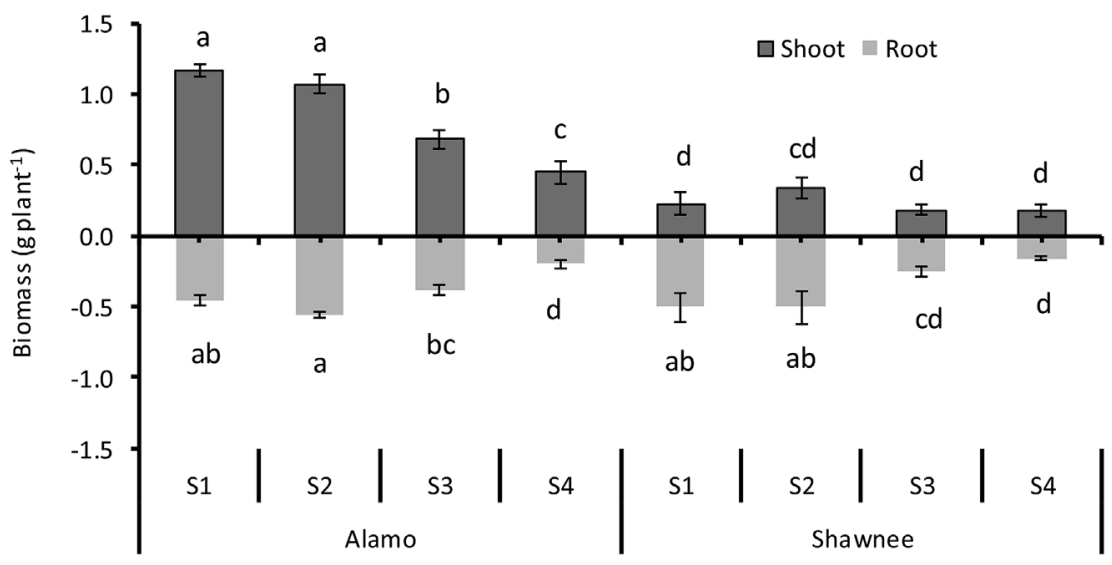

Fig. 6. Exp. 2: shoot and root dry biomass of Alamo and Shawnee at the end of the experiment in response to salinity. S1-S4 are the salinity levels $\left(0,6,8\right.$ and $14 \mathrm{dS} \mathrm{m}^{-1}$, respectively). Vertical bars: standard error of means. Different letters refer to statistically different means (Bonferroni's test, $P \leq 0.05)$ within each plant part.

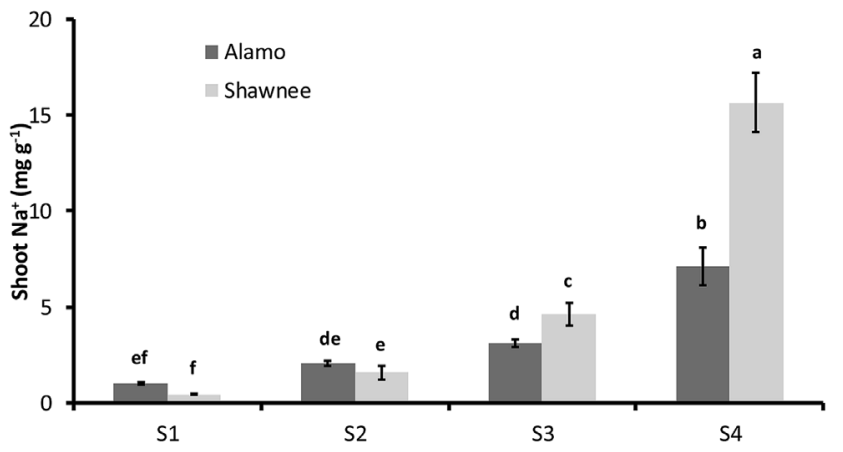

Fig. 7. Exp. 2: Shoot $\mathrm{Na}^{+}\left(\mathrm{mg} \mathrm{g}^{-1}\right)$ of Alamo and Shawnee at the end of the experiment. S1-S4 are the salinity levels $\left(0,6,8\right.$ and $14 \mathrm{dS} \mathrm{m}^{-1}$, respectively). Vertical bars: standard error of means. Different letters refer to statistically different means (Bonferroni's test, $P \leq 0.05$ ).

generally, only one salinity level has been tested $[11,31,39]$. To the best of our knowledge, this is the first study addressing a set of salinity levels on seed germination, seedlings and full-grown plants until the reproductive phase of lowland and upland switchgrass cultivars.

It is well-known that high salinity levels generally lead to osmotic stress, disrupt ion and nutritional balances, resulting in delayed germination and impaired plant development [40]. In general, germination is the most sensitive phase to salt stress, and in the case of switchgrass it can be particularly vulnerable due to its low early vigor at seedling stage [41,42]; however, the level of salt tolerance can greatly change depending on cultivar [43,44]. Alderson \& Sharp [30], for example, reported that Alamo had a moderate tolerance to salinity due to its rapid germination and the ability to maintain relatively high germination rates under salt stress and this finding is in strong agreement with the reported results. Similar conclusions were also provided by Schmer et al. [45] and Liu et al. [38]. Temperature played a role in the response of switchgrass to salinity stress and germination was generally higher at $25^{\circ} \mathrm{C}$ under all tested salinity levels, and under S4 this optimal temperature was able to significantly promote germination, partially contrasting the impairing effect of salinity. Our results showed that both Alamo (lowland) and Shawnee (upland) decreased plumular and radicular length as salinity increased, and Shawnee had a considerably lower germination rate than Alamo, in particular under critical salinity level (14 dS m ${ }^{-1}$; Fig. 2). A high and sustained germination, like that of Alamo, is indeed an important feature for homogeneous establishment and stand persistence on marginal land affected by salinity. The impaired germination of Shawnee, in particular under the highest salinity level, needs to be further investigated as other co-limiting factors related to seed morphology and size or early vigor might have been occurred.

On the other hand, at a more mature stage (Exp. 2), Alamo showed
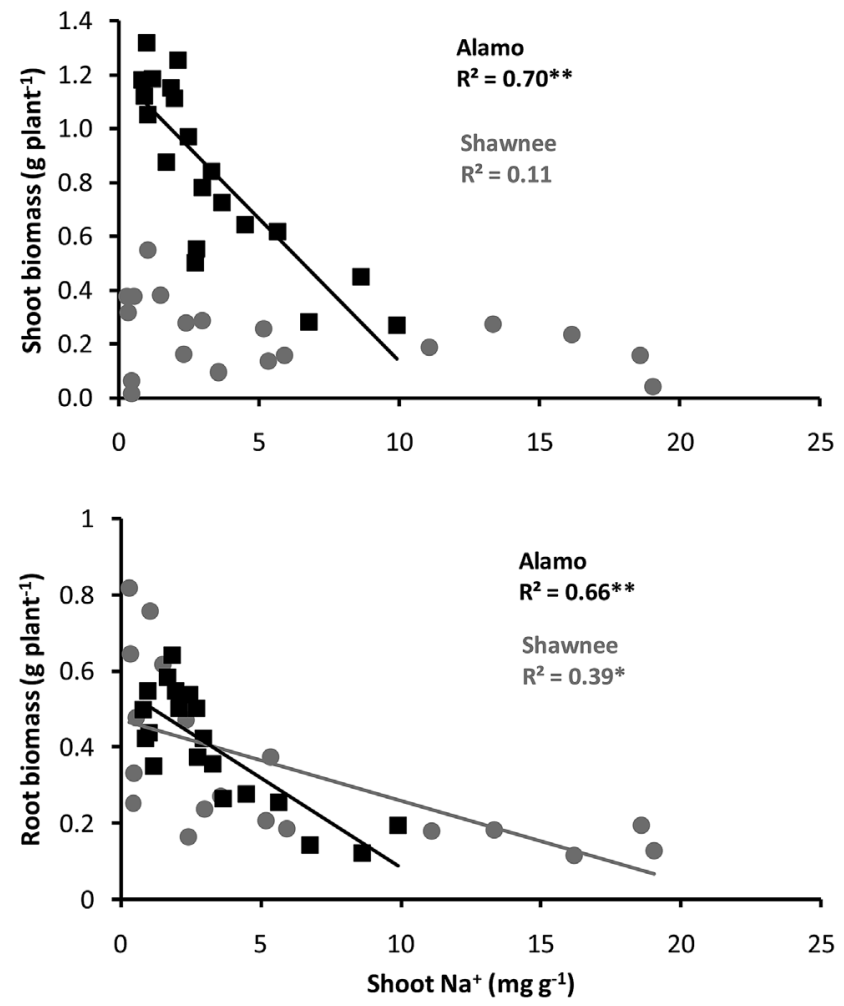

Fig. 8. Exp. 2: linear regressions between shoot (above graph) and root (below graph) biomass and shoot $\mathrm{Na}^{+}$at the end of the experiment in Alamo (black squares) and Shawnee (grey circles). * and $* *$, levels of significance of regression for $P \leq 0.05$ and $P \leq 0.01$, respectively.

Table 3

Exp. 2: intercepts and slopes of linear regressions between photosynthetic assimilation rate (Amax), maximum quantum yield ( $\mathrm{Fv} \backslash \mathrm{Fm}$ ), leaf water content (LWC), and $\mathrm{Na}^{+}$accumulated in the shoots at the end of the experiment. Different letters represent statistically difference between Alamo and Shawnee; n.s. = not significant regression.

\begin{tabular}{llll}
\hline Regression & Parameter & Alamo & Shawnee \\
\hline Amax vs. $\mathrm{Na}^{+}$ & Intercept & $9.84 \mathrm{a}$ & $6.44 \mathrm{a}$ \\
& Slope & $-1.33 \mathrm{a}$ & $-0.35 \mathrm{~b}$ \\
$\mathrm{FV} \backslash \mathrm{Fm} \mathrm{vs.} \mathrm{Na}^{+}$ & Intercept & 0.78 & n.s. \\
& Slope & -0.02 & n.s. \\
LWC vs. $\mathrm{Na}^{+}$ & Intercept & $2.08 \mathrm{a}$ & $1.87 \mathrm{a}$ \\
& Slope & $-0.09 \mathrm{a}$ & $-0.07 \mathrm{a}$ \\
& & & \\
\hline
\end{tabular}


lower salt tolerance than Shawnee likely due to osmotic and ionic effects [15]. Considering that stomatal conductance closely followed the photosynthetic trends with salinity level and time, it could be speculated that the fast accumulation of salt in the soil might have forced Alamo to close its stomata to conserve water with the consequent reduction of photosynthesis (Fig. 4). Non-stomatal inhibition of photosynthesis may, however, have also occurred in Alamo and Shawnee, as shown by the decreased $\mathrm{Fv} / \mathrm{Fm}$. The activation of such protection mechanism against photo-damage (in order to somehow maintain the balance between electron transport and carbon metabolism) suggests a low photochemistry tolerance to salinity of both cultivars, especially at salinity levels above $8 \mathrm{dS} \mathrm{m}{ }^{-1}$. LWC also decreased in both Alamo and Shawnee probably due to decreased root water uptake capacity and impaired water transport mechanisms [46] due to increasing salinity. All this led to the reported reductions in aboveground biomass accumulation $(-61 \%$ in Alamo vs. $-22 \%$ in Shawnee, S4 vs. S1, respectively, Figs. 5 and 6). In Alamo, physiological and morphological traits decreased accordingly to salinity increase, while in Shawnee clear stress symptoms were detectable only by the end of the experiment ( $>1773$ GDD) and under the highest salinity level (S4), possibly due to a delayed occurrence of indirect osmotic and/or direct ionic effects [46] (Figs. 6 and 7). Root biomass and LWC were affected by salinity in both cultivars, with the highest salinity level resulting in the most limiting condition (i.e., lowest values). The negative effect of salinity on LWC has been recently reported also on miscanthus by Stavridou et al. [4] and resulted generally associated to increased senescence evidenced as well by plants under the highest salinity level as in the present switchgrass study (Fig. 5).

The lower effect of salinity on Amax and aboveground biomass on Shawnee might be related to its higher ability to exclude salt absorption at root level. The fact that root biomass was similar in Shawnee and Alamo under each treatment and similarly affected by salt, and that the final soil electrical conductivity (that could be used in lieu of solutes concentration in the soil [14]) was significantly higher $(+56 \%)$ in Shawnee than in Alamo $(P \leq 0.05)$ at the end of Exp. 2 (Table 1 ), suggests that Shawnee roots might be able to exclude salt absorption up to a certain salt concentration, which in the present study was found to be $>8 \mathrm{dS} \mathrm{m}^{-1}$. Over this threshold, the physiological functioning of Shawnee resulted significantly disrupted (Fig. 4). The aforementioned tolerance mechanism seems to be also supported by the low correlation coefficient between $\mathrm{Na}^{+}$content in the shoot and aboveground biomass of Shawnee (Fig. 8); however, other physiological processes than exclusion like compartmentalization, accumulation of compatible solutes might have contributed to its increased salinity tolerance. For instance, the shoot $\mathrm{Na}^{+} / \mathrm{Ca}^{2+}$ ratio was almost double in Alamo than in Shawnee (data not presented) suggesting that the latter cultivar might have been able to maintain high $\mathrm{Ca}^{2+}$ concentration, and consequently ion homeostasis, while coping with salinity [47]. The response of Shawnee to salt stress is also in agreement with the results obtained by Riedell [47] with Sunburst (upland cultivar), which apparently invested in salt exclusion mechanisms, up to a threshold of $10 \mathrm{dS} \mathrm{m}^{-1}$, at cost of growth, compared to other not-excluding species (i.e., tall wheatgrass, foxtail, etc). On the contrary, Alamo was, since the very beginning of brackish water application, negatively affected by salinity but it was however able to cope with salt, confirming its moderate salinity tolerance, as suggested also by Liu et al. [39] and Kim et al. [31]. It is worth noting that Alamo, even under the highest salinity level, was more productive than Shawnee $(+250 \%$ shoot biomass). Elite cultivars, able to perform well under optimal conditions (i.e., Alamo biomass in S1 was five times greater than that of Shawnee, Figs. 6 and 7), are often best yielding also under limiting conditions [48], and this principle might apply to present saline conditions.

The set of tested salinity levels allowed to identify cultivar-specific critical response thresholds, like in Shawnee which was presumably able to exclude salt absorption at the root level in full-developed plants until the intermediate salinity level of our study $\left(>8 \mathrm{dS} \mathrm{m}^{-1}\right)$. If this trait might be genetically determined, breeding with higher yielding switchgrass genotypes would likely enlarge its cultivation basin. Until then, despite a lower salt tolerance, the cultivar choice might come down to Alamo as it clearly prevails over Shawnee in term of biomass productivity under Mediterranean saline environments.

\section{Conclusions}

The identification of bioenergy crops able to grow and produce well under marginal saline soils is a very actual topic. Among other candidate species switchgrass, in relation to the lower establishment costs and the sustained biomass productivity over a range of different environmental conditions, appears suitable for the cultivation on Mediterranean salt-affected soils. The results of the present study permitted to identify Alamo (lowland) as the best cultivar to be currently grown in the tested saline conditions, since it presented sustained germination and also it was able to overproduce Shawnee (upland) in term of biomass yield under any salinity treatments. On the other hand, Shawnee biomass productivity resulted less impaired by salinity, presumably in relation to its ability to exclude salt until a certain level $\left(<8 \mathrm{dS} \mathrm{m}^{-1}\right)$. The possibility in the future to breed salinity tolerant cultivars with those characterized by high biomass yield might permit to further increase switchgrass productivity even under marginal saline soils.

\section{Acknowledgements}

This study was funded by the European FP7 OPTIMA project "Optimization of Perennial Grasses for Biomass Production" (Grant Agreement 289642). We gratefully thank Enrico Noli for his valuable contribution to germination trials, and Livia Vittori Antisari for the elemental analysis of switchgrass biomass. Riccardo Sartoni, Filippo Lazzeri and Massimo Mondini are also thankfully acknowledged for the technical help in running the experiments.

\section{References}

[1] C.B. Field, J.E. Campbell, D.B. Lobell, Biomass energy: the scale of the potential resource, Trends Ecol. Evol. 23 (2008) 65-72

[2] A. Jones, P. Panagos, S. Barcelo, F. Bouraoui, C. Bosco, O. Dewitte, C. Gardi, M. Erhard, J. Hervás, R. Hiederer, S. Jeffery, A. Lükewille, L. Marmo, L. Montanarella, C. Olazábal, J.E. Petersen, V. Penizek, T. Strassburger, G. Tóth, M. Van Den Eeckhaut, M. Van Liedekerke, F. Verheijen, E. Viestova, Y. Yigini, The State of Soil in Europe. A Contribution of the JRC to the European Environment Agency's Environment State and Outlook Report-SOER 2010, (2012), p. 21 EUR $25186 \mathrm{EN}-$

[3] Z. Qin, Q. Zhuang, X. Cai, Bioenergy crop productivity and potential climate change mitigation from marginal lands in the United States: an ecosystem modeling perspective, GCB Bioenergy 7 (2015) 1211-1221.

[4] E. Stavridou, A. Hastings, R.J. Webster, P.R.H. Robson, The impact of soil salinity on the yield, composition and physiology of the bioenergy grass Miscanthus x giganteus, GCB Bioenergy 9 (2017) 92-104.

[5] R. Confalonieri, B. Jones, K. Van Diepen, J. Van Orshoven, Scientific Contribution on Combining Biophysical Criteria Underpinning the Delineation of Agricultural Areas Affected by Specific Constraints, (2014), p. 85 EUR 26940 EN -.

[6] EEA, Chapter 7: soil, Europe's Environment: the Dobris Assessment, European Environment Agency, 1995.

[7] G. Toth, K. Adhikari, G. Varallyay, T. Toth, K. Bodis, V. Stolbovoy, Updated map of salt affected soils in the European Union, in: G. Teth, L. Montanarella, E. Rusco (Eds.), Threats to Soil Quality in Europe EUR 23438 EN, 2008, pp. 65-77.

[8] J.L. Araus, G.A. Slafer, M.P. Reynolds, C. Royo, Plant breeding and drought in C3 cereals: what should we breed for? Ann. Bot. 89 (2002) 925-940.

[9] S.L. Cosentino, V. Copani, G. Testa, S. Sidella, G. Patanè, D. Scordia, Giant Reed screening to salinity levels, 21st European Biomass Conference and Exhibition vol. 2, ETA-Florence Renewable Energies, 978-88-89407-53-0, 2013, pp. 147-150.

[10] A.L. Fernando, S. Boleo, B. Barbosa, J. Costa, M.P. Duarte, A. Monti, Perennial grass production opportunities on marginal Mediterranean land, Bioenergy Res 8 (2015) 1523-1537.

[11] E. Sanchez, S. Gil, J. Azcòn-Bieto, S. Nogues, The response of Arundo donax L. (C3) and Panicum virgatum (C4) to different stresses, Biomass Bioenergy 85 (2016) 335-345.

[12] J. Sanchez, M.D. Curt, J. Fernandez, Approach to the potential production of giant reed in surplus saline lands of Spain, GCB Bioenergy 9 (2017) 105-118.

[13] M.B. Jones, J. Finnan, T.R. Hodkinson, Morphological and physiological traits for 
higher biomass production in perennial rhizomatous grasses grown on marginal land, GCB Bioenergy 7 (2015) 375-385.

[14] R. Munns, Comparative physiology of salt and water stress, Plant Cell Environ. 25 (2002) 239-250.

[15] R. Munns, M. Tester, Mechanisms of salinity tolerance, Annu. Rev. Plant Biol. 59 (2008) 651-681.

[16] G. Hu, Y. Liu, X. Zhang, F. Yao, Y. Huang, E.H. Ervin, B. Zhao, Physiological evaluation of alkali-salt tolerance of thirty switchgrass (Panicum virgatum) lines, PloS One 10 (7) (2015), https://doi.org/10.1371/journal.pone.0125305 6 July, 2015.

[17] S. Kim, A.L. Rayburn, T. Voigt, A. Parrish, D.K. Lee, Salinity effects on germination and plant growth of prairie cordgrass and switchgrass, Bioenergy Res 5 (2012) 225-235.

[18] W. Zegada-Lizarazu, S.D. Wullschleger, S. Surendran Nair, A. Monti, Crop physiology, in: A. Monti (Ed.), Switchgrass a Valuable Biomass Crop for Energy, Springer, Dordrecht, The Netherlands, 2012, pp. 55-86.

[19] L.E. Moser, K.P. Vogel, Switchgrass, big bluestem, and indiangrass. An introduction to grassland agriculture, in: R.F. Barnes (Ed.), Forages: an Introduction to Grassland Agriculture, Iowa State University Press, Iowa, 1995.

[20] L. Wright, A. Turhollow, Switchgrass selection as a model bioenergy crop: a history of the progress, Biomass Bioenergy 34 (2010) 851-868.

[21] I. Lewandowski, J.M.O. Shurlock, E. Lindvall, M. Christou, The development and current status of perennial rhizomatous grasses as energy crops in the US and Europe, Biomass Bioenergy 25 (2003) 335-361.

[22] D.C. Christian, H.W. Elbersen, Switchgrass (Panicum virgatum L.), in: N. El Bassam (Ed.), Energy Plant Species. Their Use and Impact on Environment and Development, James and James Publishers, London, UK, 1998, pp. 257-263.

[23] M.A. Sanderson, R.L. Reed, S.B. McLaughlin, B.V. Wullschleger, D.J. Conger, D.D. Parrish, C. Wolf, A.A. Taliaferro, W.R. Hopkins, M.A. Ocumpaugh, J.C. Hussey, J.C. Reed, C.R. Tischler, Switchgrass as a sustainable bioenergy crop, Bioresour. Technol. 56 (1996) 83-93.

[24] E. Alexopoulou, F. Zanetti, D. Scordia, W. Zegada-Lizarazu, M. Christou, G. Testa, S.L. Cosentino, A. Monti, Long-term yields of switchgrass, giant reed, and miscanthus in the Mediterranean basin, Bioenergy Res 8 (2015) 1492-1499.

[25] D. Scordia, F. Zanetti, S.S. Varga, E. Alexopoulou, V. Cavallaro, A. Monti, V. Copani, S.L. Cosentino, New insights into the propagation methods of switchgrass, miscanthus and giant reed, Bioenergy Res 8 (2015) 1480-1491.

[26] C.L. Porter, An analysis of variation between upland and lowland switchgrass, Panicum virgatum L., in central Oklahoma, Ecology 47 (1966) 980-992.

[27] M.D. Casler, Ecotypic variation among switchgrass populations from the northern USA, Crop Sci. 45 (2005) 388-398.

[28] M.D. Casler, Switchgrass breeding, genetics and genomics, in: A. Monti (Ed.), Switchgrass a Valuable Biomass Crop for Energy, Springer, Dordrecht, The Netherlands, 2012, pp. 29-53.

[29] E.R. Milano, D.B. Lowry, T.E. Juenger, The genetic basis of upland/lowland ecotype divergence in Switchgrass (Panicum virgatum), G3-Genes Genomes Genet. 6 (2016) 3561-3570.

[30] J. Alderson, W.C. Sharp, Grass Varieties in the USA, Agriculture Handbook No. 170. Soil Conservation Service, U.S. Department of Agriculture, Washington, D.C., USA,
1994, p. 296

[31] J. Kim, Y. Liu, X. Zhang, B. Zhao, K.L. Childs, Analysis of salt-induced physiological and proline changes in 46 switchgrass (Panicum virgatum) lines indicates multiple response modes, Plant Physiol. Biochem. 105 (2016) 203-212.

[32] E.K. Anderson, T.B. Voigt, S. Kim, D.K. Lee, Determining effects of sodicity and salinity on switchgrass and prairie cordgrass germination and plant growth, Ind. Crop. Prod. 64 (2015) 79-87.

[33] A. Monti, G. Bezzi, G. Pritoni, G. Venturi, Review Long-term productivity of lowland and upland switchgrass cytotypes as affected by cutting frequency, Bioresour. Technol. 99 (2008) 7425-7432.

[34] E. Kimura, S.C. Fransen, H.P. Collins, S.O. Guy, W.J. Johnston, Breaking seed dormancy of switchgrass (Panicum virgatum L.): a review, Biomass Bioenergy 80 (2015) 94-101.

[35] K.J. Moore, L.E. Moser, K.P. Vogel, S.S. Waller, B.E. Johnson, J.F. Pederson, Describing and quantifying growth stages of perennial forage grasses, Agron. J. 83 (1991) 1073-1077.

[36] M.A. Sanderson, K.J. Moore, Switchgrass morphological development predicted from day of the year or degree day models, Agron. J. 91 (1999) 732-734.

[37] T.J. Flowers, A.R. Yeo, Breeding for salinity resistance in crop plants-where next? Aust. J. Plant Physiol. 22 (1995) 875-884.

[38] J. Liu, Q. Wang, Y. Zhang, J. Cui, G. Chen, B. Xie, C. Wu, H. Liu, Synergistic and antagonistic effects of salinity and $\mathrm{pH}$ on germination in switchgrass (Panicum virgatum L.), PloS One 9 (1) (2014) e85282.

[39] Y. Liu, X. Zhang, J. Miao, L. Huang, T. Frazier, B. Zhao, Evaluation of salinity tolerance and genetic diversity of thirty-three switchgrass (Panicum virgatum) populations, Bioenergy Res 7 (2014) 1329-1342.

[40] I. Türkan, T. Demiral, Recent developments in understanding salinity tolerance, Environ. Exp. Bot. 67 (2009) 2-9.

[41] G.E. Aiken, T.L. Springer, Seed size distribution, germination, and emergence of six switchgrass cultivars, J. Range Manag. 48 (1995) 455-458.

[42] A. Monti, P. Venturi, H.W. Elbersen, Evaluation of the establishment of lowland and upland switchgrass (Panicum virgatum L.) varieties under different tillage and seedbed conditions in northern Italy, Soil Tillage Res. 63 (2001) 75-83.

[43] F.H. Hsu, C.J. Nelson, A.G. Matches, Temperature effects on germination of perennial warm-season forage grasses, Crop Sci. 25 (1985) 215-220.

[44] P.R. Newman, L.E. Moser, Seedling root development and morphology of coolseason and warm-season forage grasses, Crop Sci. 28 (1988) 148-151.

[45] M.R. Schmer, Q. Xue, J.R. Hendrickson, Salinity effects on perennial, warm-season $\left(\mathrm{C}_{4}\right)$ grass germination adapted to Northern Great Plains, Can. J. Plant Sci. 92 (2012) 873-881.

[46] R. Munns, M. Gilliham, Salinity tolerance of crops - what is the cost? New Phytol. 208 (2015) 668-673.

[47] W.E. Riedell, Growth and ion accumulation responses of four grass species to salinity, J. Plant Nutr. 14 (2016) 2115-2125.

[48] R.A. Richards, J.R. Hunt, J.A. Kirkegaard, J.B. Passioura, Yield improvement and adaptation of wheat to water-limited environments in Australia - a case study, Crop Pasture Sci. 65 (2014) 676-689. 